\title{
Image markers as predictors of response in neovascular age-related macular degeneration treated with ranibizumab
}

\section{Marcadores de imagen como predictores de respuesta en la degeneración macular neovascular asociada a la edad tratada con ranibizumab}

\author{
Claudia Acosta ${ }^{1,2 *}$, Carolina Sardi ${ }^{1,2}$, Julián Espinosa ${ }^{3}$, María E. Mejía ${ }^{4}$, Juan G. Sánchez ${ }^{1,2}$, \\ Mauricio Arango ${ }^{1}$, Elsa M. Vásquez ${ }^{5}$ and Manuela Colorado ${ }^{6}$ \\ ${ }^{1}$ Ophthalmology clinic in Antioquia Clofán; ${ }^{2}$ Instituto Nacional de Investigación en Oftalmología, INIO; ${ }^{3}$ Postgraduate of Ophthalmology, Universidad \\ CES; ${ }^{4}$ Facultad de Medicina, Universidad CES; ${ }^{5}$ Research Division, Facultad de Medicina, Universidad CES; ${ }^{6}$ Medical doctor, Instituto Nacional \\ de Investigación en Oftalmología, INIO. Medellin, Colombia
}

\begin{abstract}
Objective: To identify features in enhanced depth imaging spectral-domain optical coherence tomography (SD-OCT), fluorescein angiography (FA), and fundus auto fluorescence (FAF) of patients with neovascular age-related macular degeneration ( $N A M D)$, as image markers of poor response to intravitreal Ranibizumab therapy. Methods: Descriptive, comparative, cross sectional study. We evaluated the clinical charts of patients with nAMD on intravitreal Ranibizumab therapy. Subjects were divided into 2 groups: those with good response to Ranibizumab (G1) and those with poor response to therapy (G2). All patients underwent wide field fundus FA, wide field FAF and SD-OCT. Absolute and relative frequencies, strength of association (chi2) and prevalence ratio, with a 95\% significance level were calculated. Results: The analysis included 30 eyes, 15 eyes in G1 and 15 eyes in G2. We found a statistically significant correlation between poor responders and the presence of external tubulations ( $p=0.03)$. In the good responder group there was significant correlation with the presence of sub retinal fluid ( $p=0.04)$, absence of sub retinal thickening $(p<0.01)$, absence of fibrosis at the FA $(p=0.02)$ and presence of hyper-auto fluorescent findings on the FAF ( $p \leq 0.01)$. Conclusion: The identification of image markers prior to treatment could help predict the response to ranibizumab therapy in nAMD patients. The presence of sub retinal fluid, absence of sub retinal thickening, absence of fibrosis and presence of hyper-auto fluorescent were associated with good responder. These markers, plus initial visual acuity can be used as a guide for categorization of patients according to response expectation, and therefore tailor the follow up scheme.
\end{abstract}

Key words: Macular degeneration. Image markers. Optical coherence tomography. Fluorescein angiography. Fundus auto fluorescence. Ranibizumab.

\section{Resumen}

Objetivos: Identificar características en tomografía de coherencia óptica de dominio espectral (SD-OCT), angiografía fluoresceínica (FA) y autofluorescencia de fondo (FAF) de pacientes con degeneración macular neovascular asociada a la edad (DMREn) como marcadores de pobre respuesta a la terapia con ranibizumab intravítreo. Métodos: Estudio transversal,

Correspondence:

${ }^{*}$ Claudia Acosta

Clínica Clofán, Consultorio 1221

Carrera 48 No. $19^{\mathrm{a}}-40$

Date of reception: 05-02-2018

Date of acceptance: 05-07-2018

Medellin, Colombia

DOI: 10.24875/RMOE.M18000027
Available online: 17-09-2018 Rev Mex Oftalmol (Eng). 2018;92(5):215-221 www.rmo.com.mx the CC BY-NC-ND 2604-1731/@ 2018 Sociedad Mexicana de Oftalmología. Publs
license (http://creativecommons.org/licenses/by-nc-nd/4.0/). 
comparativo y descriptivo. Se evaluaron las historias clínicas de pacientes con DMREn en tratamiento con ranibizumab intravítreo. Los participantes se dividieron en 2 grupos: aquellos con buena respuesta a ranibizumab (G1) y aquellos con pobre respuesta al tratamiento (G2). A todos los pacientes se les realizó FA, FAF y SD-OCT en el momento del diagnóstico y a los 6 meses. Se calcularon frecuencias absolutas y relativas, fortaleza de asociación (chi2) y razón de prevalencia, con nivel de significancia del 95\%. Resultados: El análisis incluyó 30 ojos, 15 en G1 y 15 en G2. Se encontró una correlación significativa entre pacientes con pobre respuesta y la presencia de tubulaciones externas $(p=0.03)$. En el grupo con buena respuesta hubo correlación significativa con la presencia de fluido subretiniano $(p=0.04)$, ausencia de engrosamiento subretiniano $(p<0.01)$, ausencia de fibrosis en la $F A(p=0.02)$ y hallazgos hiperautofluorescentes en la $F A F(p \leq 0.01)$. Conclusiones: La identificación de marcadores de imagen en pacientes con DMREn podría ayudar a predecir la respuesta a la terapia con ranibizumab. La presencia de fluido subretiniano, ausencia de engrosamiento subretiniano, ausencia de fibrosis y hallazgos hiperautofluorescentes se asociaron a buena respuesta. Estos marcadores, más la agudeza visual inicial, podrían usarse como guía para la categorización de pacientes de acuerdo a las expectativas de respuesta, y así ajustar el esquema de seguimiento.

Palabras clave: Degeneración Macular. Marcadores de imagen. Tomografía de coherencia óptica. Angiografía fluoresceínica. Autofluorescencia de fondo. Ranibizumab.

\section{Introduction}

Age-related macular degeneration (AMD) is the leading cause of irreversible visual loss in developed countries and has a huge impact on health system costs ${ }^{1,2}$. The advent of intravitreal ranibizumab, a monoclonal antibody directed against vascular endothelial growth factor $A$ (VEGF-A) isoforms, represents a significant change from previously available treatments for neovascular age-related macular degeneration (NAMD), and currently is considered the "gold standard» treatment ${ }^{3,4}$.

Randomized clinical trials have shown that a monthly scheme with ranibizumab is effective in preventing visual loss and capable of significantly improving visual acuity (VA) in up to one third of patients with subfoveal $\mathrm{NAMD}^{3,5}$. However, monthly injections result in a burden for the patient and in high costs for the health system $^{6}$; therefore, a reduction in the frequency of treatment without losing effectiveness would be desirable. The Prospective Optical Coherence Tomography Imaging of Patients with Neovascular Age-Related Macular Degeneration Treated with Intraocular Ranibizumab (PrONTO) study showed that, after 3 monthly injections with ranibizumab, the treatment guided by optical coherence tomography (OCT) provides similar results to monthly doses of the medication ${ }^{7}$. Other studies have indicated that the results of pro-re-nata (PRN) doses are variable ${ }^{8,9}$.

Approximately 20 to $30 \%$ of patients may show a poor response to treatment (defined as a loss of more than five Early Treatment Diabetic Retinopathy Study [ETDRS] letters). Initial VA has been identified as the most influential predictor for the change from initial VA to 24 months, followed by the size of choroidal neovascularization (CNV) and the age of the patient ${ }^{10}$. Identifying prognostic indicators of response would allow designing treatment schemes oriented to the type of response of each patient.

The purpose of this study was to identify baseline characteristics by spectral-domain optical coherence tomography (SD-OCT), fluorescein angiography (FA), and fundus auto fluorescence (FAF) of patients with NAMD as markers that correlate with poor or good response to treatment with intravitreal ranibizumab.

\section{Methods}

Transversal, descriptive and analytical study, which involved the review of medical charts and SD-OCT, FA and FAF images of patients diagnosed with NAMD evaluated at the Ophthalmology Clinic of Antioquia - Clofán, Medellin, Colombia, between October 31, 2013 and March 30, 2015. An Institutional Review Board and Independent Ethics Committee and the Medical Studies Committee approved this study; all participants signed an informed consent form to enter the study. The study adhered to the principles of the Declaration of Helsinki of 1975 , in the revised version of 1983.

Patients 55 years of age or older, of both sexes, of any race or ethnicity with a confirmed diagnosis of NAMD in at least one eye, who had FA, wide-field FAF (Optos 200Tx, Dunfermline, UK) and SD-OCT were included (RTVue, Optovue Inc., Freemont, CA, USA) prior to the start of anti-angiogenic treatment and also at 6 months after treatment. Baseline OCT described the evaluated characteristics. The OCT after 6 months of treatment served to classify patients according to the inclusion criteria as non-responders or responders. 
Patients also had to have a complete ophthalmological examination as part of their evaluation, prior to receiving any ocular treatment, and they had to comply with the loading dose of 3 intravitreal injections of ranibizumab (Lucentis ${ }^{\circledR}$, Genentech, San Francisco, CA, USA), followed by a fixed monthly schedule or PRN with at least 6 months of follow-up.

Then, a group of patients with poor response to treatment (G2) was selected, defined as patients who, after the 3 monthly loading doses and a fixed schedule or PRN, following the PrONTO 7 study protocol, lost more than 5 ETDRS letters and did not show a reduction in macular thickness or in the amount of sub retinal fluid by SD-OCT. The controls were patients who showed good response to treatment (G1), that is, they achieved an improvement in best-corrected visual acuity (BCVA) and stability during the 6 months of follow-up. In order to control for age and sex variables, both groups were matched for these characteristics ( \pm 3 years).

Patients with any of the following characteristics were excluded: smokers, concomitant ocular disease in the studied eye that would interfere with VA improvement, idiopathic macular hole in the contralateral eye, previous vitrectomy, previous treatment for NAMD, previous use of intraocular or periocular steroids, previous use of another anti-VEGF agent, any form of combination therapy, CNV attributable to a different cause of NAMD, intraocular surgery in the previous 6 months, previous macular laser treatment, any other ocular laser treatment in the previous 3 months, ocular disease (including severe dry eye) that could, according to the judgement of the authors, make it difficult to perform the study examinations, suspected or known allergy to fluorescein, ocular axial length greater than $26 \mathrm{~mm}$ or refractive defect $\pm 3.00 \mathrm{D}$ and fibrovascular scar. Patients with an initial BCVA better than 40 ETDRS letters (equivalent to $0.3 \log M A R, 20 / 20$ Snellen or 0.50 decimal) were also excluded from the study, since one of the criteria to define patients with poor response was the loss of more than five ETDRS letters. Finally, the failure to improve to a 20/20 VA did not mean lack of response.

\section{Morphological characteristics by optical coherence tomography}

The characteristics of the intraretinal architecture were analyzed in the subfoveal area $(6 \mathrm{~mm})$. We evaluated: loss of integrity of the external limiting membrane $(E L M)^{11}$, absence of small dense particles ${ }^{12}$, loss of the ellipsoid zone integrity, presuming a junction of the external/internal photoreceptor segments ${ }^{11}$, absence of sub retinal thickening (sub retinal thickening defined as a homogenous layer of hyper reflectivity of the band below the ELM, extending to the band representing the pigmented epithelium of the retina - this variable is a qualitative one-), presence of retinal external tubulations $^{13,14}$, absence of vitreomacular traction or epiretinal membrane ${ }^{15}$, presence of retinal pigment epithelium detachment (RPED) ${ }^{16}$, evidence of outer segment stalactites $^{17}$, absence of geographic atrophy, presence of diffuse edema, presence of choroidal thinning or alteration of normal choroidal anatomy based on normal choroidal thickness values ${ }^{18}$ (choroidal thickness was measured from the external aspect of the hyper reflective line corresponding to the retinal pigment epithelium (RPE) to the inner side of the subfoveal sclero-choroidal junction, at intervals of 500 from the fovea to the nasal and temporal sector, until completing 5 measurements), absence of intraretinal cysts and sub retinal fluid ${ }^{19}$.

\section{Characteristics by wide field fluorescein angiography}

The characteristics analyzed by FA were absence of fibrosis, absence of leakage, presence of hemorrhage, presence of occult CNV and CNV size (taking disk diameter as the measurement unit).

\section{Characteristics by wide-field fundus auto fluorescence}

The presence of a hyper-auto fluorescent or hypo-auto fluorescent pattern was analyzed, both in the posterior pole and in the peripheral retina.

All SD-OCT, FA and FAF images were evaluated by an experienced reviewer (C.A) masked for the dependent variable (response to treatment) and the rest of the covariables collected. For quantitative variables, dispersion and central tendency measures were used, while for qualitative variables, absolute and relative proportions were obtained. The Chi-square test was used and the prevalence ratio (PR) was determined to compare proportions of some characteristics between good responders and poor responders, with a 95\% significance level. The software used for the analysis of the information was SPSS version 18, and data were tabulated in Microsoft Excel 2016.

\section{Results}

Fifteen eyes of 15 patients were selected for each group. All the participants were Hispanic. The average 
Table 1. Epidemiological data and baseline characteristics

\begin{tabular}{|c|c|c|c|c|}
\hline & G1 & G2 & \multirow[t]{2}{*}{ p } & \\
\hline & $n=15$ & $n=15$ & & $\infty$ \\
\hline $\begin{array}{l}\text { Sex } \\
\text { Female, n (\%) } \\
\text { Male, n (\%) }\end{array}$ & $\begin{array}{c}10(66 \%) \\
5(33.3 \%)\end{array}$ & $\begin{array}{c}7(46 \%) \\
8(53.3 \%)\end{array}$ & 0.269 & $9 \stackrel{\frac{1}{2}}{\frac{1}{2}}$ \\
\hline Presence of HTA, n (\%) & $9(60 \%)$ & $8(53 \%)$ & \multicolumn{2}{|c|}{0.713} \\
\hline Presence of MD, $\mathrm{n}(\%)$ & $2(13.3 \%)$ & $0(0 \%)$ & \multicolumn{2}{|c|}{$0.143^{\circ}$} \\
\hline Presence of cardiovascular disease, $\mathrm{n}(\%)$ & $2(13.3 \%)$ & $2(13.3 \%)$ & 1 & 웅 \\
\hline Smoker/former smoker, n (\%) & $5(33.3 \%)$ & $6(40 \%)$ & \multicolumn{2}{|c|}{0.705} \\
\hline $\begin{array}{l}\text { Study eye } \\
\text { OD, n (\%) } \\
\text { OS, n (\%) }\end{array}$ & $\begin{array}{c}3(20 \%) \\
12(80 \%)\end{array}$ & $\begin{array}{l}9(60 \%) \\
6(40 \%)\end{array}$ & 0.025 & 25 \\
\hline Age, mean \pm SD & $72.66 \pm 10.72$ & $72.13 \pm 11.36$ & - & ○ \\
\hline Average of injections, median P25-P75 & $10.8-14$ & $10.8-15$ & - & " \\
\hline BCVA, median P25-P75 (ETDRS) & $45.22-50$ & $32.3-45$ & - & $\frac{\varepsilon}{2}$ \\
\hline
\end{tabular}
Treatment Diabetic Retinopathy Study; HT: arterial hypertension; OD: right eye; OS: left eye; BCVA: best corrected visual acuity.

age of the patients was $72.66 \pm 10.72$ years and $72.13 \pm 11.36$ years in $\mathrm{G} 1$ and $\mathrm{G} 2$, respectively. Table 1 summarizes the baseline characteristics of the patients.

\section{Characteristics by spectral-domain optical coherence tomography}

The frequency of findings by SD-OCT overall and for each group is listed in detail in table 2. The most frequent finding in $\mathrm{G} 1$ was the absence of sub retinal thickening in $72.20 \%$ of the eyes. On the other hand, the most frequent finding by SD-OCT in G2 was the presence of external tubulations in $100 \%$ of the eyes (Fig. 1). A statistically significant association was observed between a good response to treatment and the absence of sub retinal thickening ( $p<0.01$; PR: 13) (Fig. 2) as well as the presence of sub retinal fluid ( $p=0.04$; PR: 5.6) (Fig. 3); and a statistically significant association between a poor response to treatment and the presence of retinal external tubulations $(p=0.03$; PR: 1.36) (Fig. 1).

\section{Characteristics by fluorescein angiography}

The frequency of findings by FA are listed in detail in table 3 . We observed a statistically significant association between the group with good response to treatment

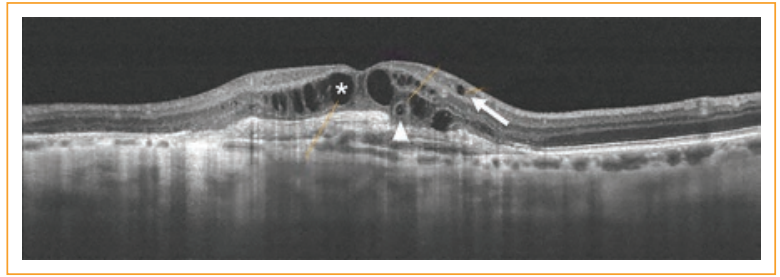

Figure 1. SD - OCT showing retinal external tubulations (arrowhead), pseudo cyst in the external retina (white asterisk) and pseudo cyst in the internal retina (white arrow).

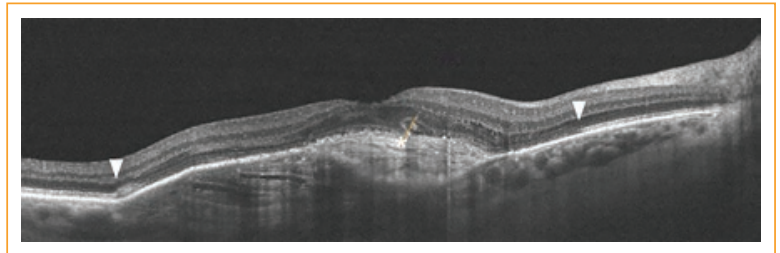

Figure 2. SD - OCT showing loss of integrity of the ellipsoid zone (arrowheads) and sub retinal thickening (white asterisk).

and the absence of fibrosis ( $p=0.02$; PR: 7.4). No statistically significant correlation was observed between response to treatment and CNV size $(p=0.47)$. The most frequent CNV type was occult CNV, observed in $50 \%$ of the eyes in each group (Table 3 ). 
Table 2. Comparison of OCT characteristics of eyes with age-related macular degeneration at the beginning of the study, between good responders and poor responders to ranibizumab therapy. Total frequencies and P values are shown

\begin{tabular}{|c|c|c|c|c|c|c|c|}
\hline SD-OCT findings & G1 & & G2 & & $\mathbf{p}$ & RP & $\mathrm{GH}$ \\
\hline Foveal depression preserved & 8 & $66.70 \%$ & 4 & $33.30 \%$ & 0.13 & 3.14 & $0.6-14.5$ \\
\hline ELM integrity loss & 6 & $37.50 \%$ & 10 & $62.50 \%$ & 0.14 & 3 & $0.6-13.3$ \\
\hline Absence of small dense particles & 9 & $64.30 \%$ & 5 & $35.70 \%$ & 0.14 & 3 & $0.67-13.3$ \\
\hline Ellipsoid zone integrity loss & 7 & $38.90 \%$ & 11 & $61.10 \%$ & 0.13 & 3.1 & $0.6-14.5$ \\
\hline Absence of sub retinal thickening & 13 & $72.20 \%$ & 5 & $27.80 \%$ & $<0.01$ & 13 & 2.07-81.4 \\
\hline Presence of external tubulations & 0 & $0 \%$ & 4 & $100 \%$ & 0.03 & 2.3 & $1.5-3.7$ \\
\hline Absence of vitreomacular traction & 14 & $54 \%$ & 12 & $46 \%$ & 0.28 & 3.5 & $0.32-38.2$ \\
\hline RPE detachment & 8 & $57.10 \%$ & 6 & $42.90 \%$ & 0.46 & 1.71 & $0.4-7.2$ \\
\hline Outer segment stalactites & 3 & $50 \%$ & 3 & $50 \%$ & 1 & 1 & $0.1-5.9$ \\
\hline Absence of geographic atrophy & 11 & $61.10 \%$ & 7 & $38.90 \%$ & 0.13 & 3.1 & $0.68-14.5$ \\
\hline Presence of diffuse edema & 7 & $53.80 \%$ & 6 & $46.20 \%$ & 0.71 & 1.3 & $0.3-5.5$ \\
\hline Absence of intra retinal cysts & 9 & $56.30 \%$ & 7 & $43.80 \%$ & 0.46 & 1.7 & $0.4-7.2$ \\
\hline Presence of sub retinal fluid & 13 & $61.90 \%$ & 8 & $38.10 \%$ & 0.04 & 5.6 & $0.9-34.4$ \\
\hline Choroidal thinning & 6 & $60 \%$ & 4 & $40 \%$ & 0.43 & 1.8 & $0.3-8.5$ \\
\hline
\end{tabular}

The numbers correspond to the number of eyes with that finding and the percentage is the frequency of that finding within the group. RPE: retinal pigment epithelium; G1: patients with good response to ranibizumab; G2: patients with poor response to ranibizumab; ELM: external limiting membrane; SD-OCT: spectral-domain optical coherence tomography.

Table 3. Comparison of OCT characteristics by FA of eyes with age-related macular degeneration at the beginning of the study, between good responders and poor responders to ranibizumab therapy. Total frequencies and $\mathrm{P}$ values are shown

\begin{tabular}{|c|c|c|c|c|c|c|c|}
\hline Characteristics by FA & G1 & $n=15$ & G2 & $n=15$ & $\mathbf{p}$ & RP & CPI \\
\hline CNV, occult type & 12 & $50 \%$ & 12 & $50 \%$ & 1 & 1 & $0.16-5.98$ \\
\hline Absence of fibrosis & 13 & $65 \%$ & 7 & $35 \%$ & 0.02 & 7.4 & $1.2-45.0$ \\
\hline Presence of hemorrhage & 0 & $0 \%$ & 1 & $100 \%$ & 0.3 & 1.07 & $0.93-1.22$ \\
\hline Absence of leakage & 12 & $60 \%$ & 8 & $40 \%$ & 0.12 & 3.5 & $0.69-17.7$ \\
\hline Neovascular membrane $>2$ DD & 5 & $35.7 \%$ & 3 & $23.10 \%$ & 0.47 & 1.8 & $0.34-10.0$ \\
\hline Hyper-auto fluorescent FAF & 8 & $88.90 \%$ & 1 & $11.10 \%$ & $<0.01$ & 21.3 & $1.8-252.2$ \\
\hline
\end{tabular}

DD: disk diameter; FA: fluorescein angiography; FAF: fundus auto fluorescence; G1: patients with good response to ranibizumab; G2: patients with poor response to ranibizumab; CNV: choroidal neovascularization.

\section{Characteristics by fundus auto fluorescence}

FAF findings are described in table 3 . The presence of a hyper-auto fluorescent pattern was observed in $88.90 \%$ in $G 1$ ( $p \leq 0.01, P R, 21.3)$ and in $11.10 \%$ in $G 2$ (Figs. 4 and 5), as well as a statistically significant association between hyper-auto fluorescent findings and good response to treatment ( $p \leq 0.01, P R 21.3$ ). We did not evaluate if there was a relationship with the area.

\section{Discussion}

The identification of image markers has gained great relevance in recent years in the field of ophthalmology 


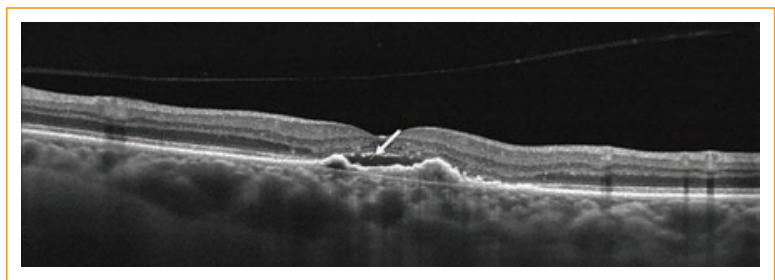

Figure 3. SD - OCT showing sub retinal fluid (white arrow).

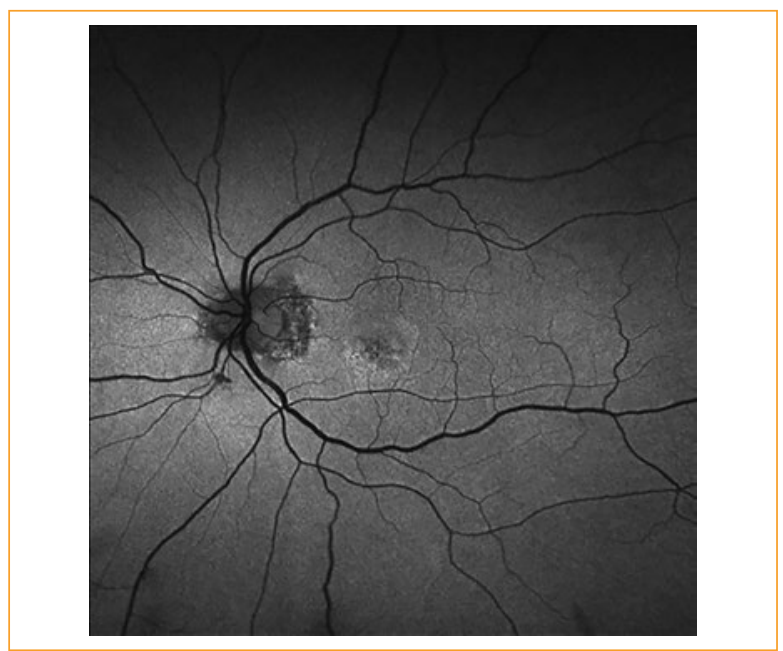

Figure 4. Fundus auto fluorescence of the left eye showing a focal hyper auto fluorescence pattern.

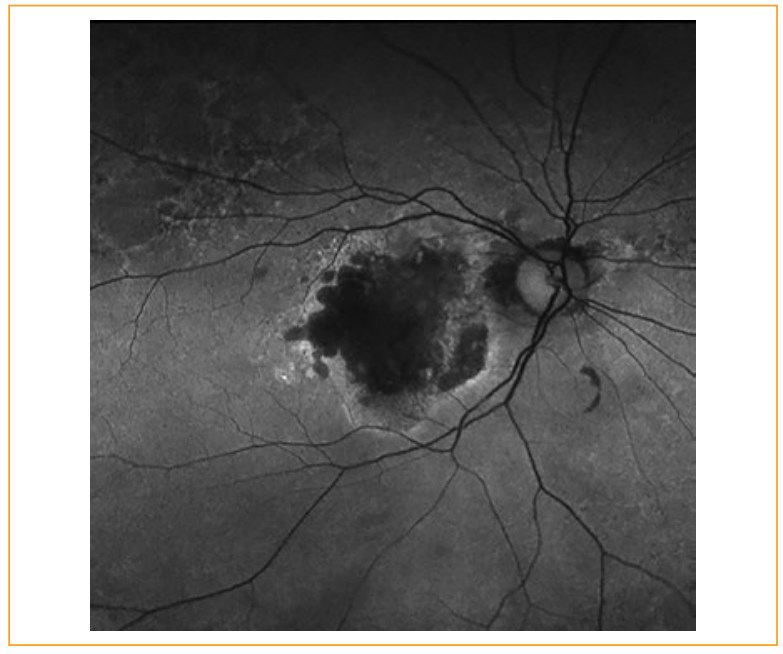

Figure 5. Fundus auto fluorescence of the right eye showing a central hypo auto fluorescence pattern surrounded by a hyper auto fluorescence halo.

and specifically for retina specialists. Their identification in the treatment of AMD may influence the treatment scheme. This will be reflected not only in the anatomical and functional results, but also in the decrease in the burden for the patient and in the costs for the health system ${ }^{6}$. Clinical findings such as $\mathrm{VA}^{10}$ and retinal thickness $^{20}$ are recognized as image markers ${ }^{21}$.

Advances in OCT technology, such as ultra-high resolution and the advent of wide-field auto fluorescence and angiography, allow the evaluation of new features in AMD. Previous publications have established that ELM alterations ${ }^{17,22}$, as well as the presence of RPED ${ }^{23}$, among other characteristics by OCT, correlate with poor treatment response to antiangiogenic agents. Some authors have classified patients according to their response to treatment ${ }^{24}$, and categorizing patients into responders or poor responders has been controversial. We rely on functional and morphological results to determine if the patient is a responder or a poor responder.

In our study, some characteristics by SD-OCT, such as the absence of sub retinal thickening and the presence of sub retinal fluid, correlated with a good treatment response to ranibizumab. The absence of sub retinal thickening in our sample was associated with a 12-fold better response to treatment. On the other hand, the presence of sub retinal fluid was associated with a 4-fold better response. Our hypothesis of why the presence of sub retinal fluid correlated with a better response to treatment is that if there is a more preserved retinal cell structure, the fluid remains in the sub retinal space, protecting the inner layers of the retina.

FA findings were not very useful to predict treatment response; however, the absence of fibrosis correlated with a favorable response, and the absence of fibrosis by FA correlated with a 6 -fold improvement in treatment response compared to those eyes that showed fibrosis by FA. Additionally, $50 \%$ of the eyes showed occult CNV, so no association could be established with response to ranibizumab. This result differs from other published reports ${ }^{25}$.

Within the limitations of this study, the main one was the sample size, since only patients who had a strict follow-up and adherence to the protocols were included. This explains why the number of patients included in the study was low. Although the exploratory nature of this study allows the identification of some relevant markers, studies with a larger sample are required to establish significant differences.

The identification of image markers in patients with NAMD could help predict response to ranibizumab therapy. External tubulations and sub retinal fibrosis were associated with poor response, as they are signs of marked deterioration of cellular structures. These markers, 
plus the initial VA, may be useful as a guide for patient classification according to the response prognosis, and thus to adjust the follow-up scheme.

\section{Conclusions}

The identification of image markers in patients with NAMD could help predict response to ranibizumab therapy.

The presence of sub retinal fluid, absence of sub retinal thickening, absence of fibrosis and hyper-auto fluorescent findings correlated with a good response. These markers, plus the initial VA, may be useful as prognostic factors, and thus to adjust the follow-up scheme. However, with our small sample, these results are not considered conclusive.

\section{Ethical disclosures}

Protection of human and animal subjects. The authors declare that no experiments were performed on humans or animals for this study.

Confidentiality of data. The authors declare that they have followed the protocols of their work center on the publication of patient data.

Right to privacy and informed consent. The authors declare that no patient data appear in this article.

\section{Conflicts of interest}

The authors state that they have received financial support from Novartis ${ }^{\circledR}$ to carry out this research.

\section{References}

1. Klein R, Peto T, Bird A, Vannewkirk MR. The epidemiology of age-related macular degeneration. Am J Ophthalmol. 2004;137(3):486-95.

2. Rein DB, Zhang P, Wirth KE, Lee PP, Hoerger TJ, McCall N, et al. The economic burden of major adult visual disorders in the United States. Arch Ophthalmol. 2006;124:1754-60

3. Brown DM, Kaiser PK, Michaels M, Soubrane G, Heier JS, Kim RY, et al. Ranibizumab versus verteporfin for neovascular age-related macular degeneration. N Engl J Med. 2006;355(14):1432-44

4. Regillo CD, Brown DM, Abraham P, Yue H, lanchulev T, Schneider S, et al. Randomized, double-masked, sham-controlled trial of ranibizumab for neovascular age related macular degeneration: PIER Study year 1. Am J Ophthalmol. 2008;145:239-48.

5. Rosenfeld PJ, Brown DM, Heier JS, Boyer DS, Kaiser PK, Chung CY, et al. Ranibizumab for neovascular age-related macular degeneration. N Engl J Med. 2006;355(14):1419-31
6. Boyer DS, Antoszyk AN, Awh CC, Bhisitkul RB, Shapiro H, Acharya NR MARINA Study Group. Subgroup analysis of the MARINA study of ranibizumab in neovascular age-related macular degeneration. Ophthalmology. 2007;114(2):246-52.

7. Fung AE, Lalwani GA, Rosenfeld PJ, Dubovy SR, Michels S, Feuer WJ, et al. An optical coherence tomography-guided, variable dosing regimen with intravitreal ranibizumab (Lucentis) for neovascular age-related macular degeneration. Am J Ophthalmol. 2007:143(4):566-83.

8. Gupta B, Adewoyin T, Patel SK, Sivaprasad S. Comparison of two intravitreal ranibizumab treatment schedules for neovascular age-related macular degeneration. Br J Ophthalmol. 2011;95(3):386-90

9. Cohen SY, Dubois L, Tadayoni R, Fajnkuchen F, Nghiem-Buffet S, et al. Results of one-year's treatment with ranibizumab for exudative age-related macular degeneration in a clinical setting. Am J Ophthalmol. 2009; 148(3):409-13.

10. Tsilimbaris MK, López-Gálvez MI, Gallego-Pinazo R, Margaron P, Lambrou GN. Epidemiological and Clinical Baseline Characteristics as Predictive Biomarkers of Response to Anti-VEGF Treatment in Patients with Neovascular AMD. J Ophthalmol. 2016;2016:4367631.

11. Gamulescu MA, Panagakis G, Theek C, Helbig H. Predictive Factors in OCT Analysis for Visual Outcome in Exudative AMD. JOphthal. 2012:851684

12. Framme C, Wolf $\mathrm{S}$, Wolf-Schnurrbusch $\mathrm{U}$. Small dense particles in the retina observable by spectral-domain optical coherence tomography in age-related macular degeneration. Invest Ophthalmol Vis Sci. 2010; 51(11):5965-9

13. Zweifel SA, Engelbert M, Laud K, Margolis R, Spaide RF, Freund KB. Outer retinal tubulation: a novel optical coherence tomography finding. Arch Ophthalmol. 2009:127(12):1596-602.

14. Wolff B, Matet A, Vasseur V, Sahel JA, Mauget-Faÿsse M. En Face OCT Imaging for the Diagnosis of Outer Retinal Tubulations in Age-Related Macular Degeneration. J Ophthalmol. 2012;2012:542417.

15. Mojana F, Cheng L, Bartsch DU, Silva GA, Kozak I, Nigam N, Freeman WR. The role of abnormal vitreomacular adhesion in age-related macular degeneration: spectral optical coherence tomography and surgical results. Am J Ophthalmol. 2008;146(2):218-27.

16. Ahlers C, Golbaz I, Einwallner E, Dunavölgyi R, Malamos P, Stock G, Pruente C, Schmidt-Erfurth U. Identification of optical density ratios in sub retinal fluid as a clinically relevant biomarker in exudative macular disease. Invest Ophthalmol Vis Sci. 2009;50(7):3417-24.

17. Mathew R, Richardson M, Sivaprasad S. Predictive value of spectral-domain optical coherence tomography features in assessment of visual prognosis in eyes with neovascular age-related macular degeneration treated with ranibizumab. Am J Ophthalmol. 2013;155(4):720-6.e1.

18. Sardi Correa C, Acosta Cadavid C, Rodríguez Gómez A, Mejía Estrada M, Vásquez Trespalacios E. Grosor coroideo central en sujetos hispanos sanos medido por tomografía de coherencia óptica con imagen de profundidad mejorada. Revista Mexicana de Oftalmología. 2017;91(1):2-8.

19. Nakajima $H$, Mizota A, Tanaka M. Technical note: method for estimating volume of sub retinal fluid in cases of localized retinal detachment by OCT ophthalmoscopy. Ophthalmic Physiol Opt. 2007;27(5):512-7.

20. Brown DM, Tuomi L, Shapiro H. Pier Study Group. Anatomicalmeasures as predictors of visual outcomes in ranibizumab-treated eyes with neovascular age-related macular degeneration. Retina. 2013;33(1):23-34.

21. Singh RP, Fu EX, Smith SD, Williams DR, Kaiser PK. Predictive factors of visual and anatomical outcome after intravitreal bevacizumab treatment of neovascular agerelated macular degeneration: an optical coherence tomography study. Br J Ophthalmol. 2009;1353-8.

22. Roberts $\mathrm{P}$, Mittermueller TJ, Montuoro A, Sulzbacher F, Munk M, Sacu S, Schmidt-Erfurth U. A quantitative approach to identify morphological features relevant for visual function in ranibizumab therapy of neovascular AMD. Invest Ophthalmol Vis Sci. 2014;55(10):6623-30.

23. Young M, Forooghian F. Serous Index of Pigment Epithelial Detachments in Neovascular Age-Related Macular Degeneration Predicts Response to Anti-Vascular Endothelial Growth Factor Treatment. Ophthalmic Surg Lasers Imaging Retina. 2015;46(7):724-7.

24. Yang S, Zhao J, Sun X. Resistance to anti-VEGF therapy in neovascular age-related macular degeneration: a comprehensive review. Drug Design, Development and Therapy. 2016;10:1857-67.

25. Otsuii T, Nagai Y, Sho K, Tsumura A, Koike N, Tsuda M, Nishimura T, Takahashi K. Initial non-responders to ranibizumab in the treatment of age-related macular degeneration (AMD). Clin Ophthalmol. 2013; 7: $1487-90$. 